\title{
O Novo Regime Fiscal: tramitação e impactos para a educação
}

\author{
The New Fiscal Policy: processing and impacts for education \\ El Nuevo Régimen Fiscal: tramitación e impactos para la educación
}

CLEITON DE OLIVEIRA GUARACY SILVA

\begin{abstract}
Resumo: O estudo analisa a tramitação do Novo Regime Fiscal no Congresso Nacional, considerando seus impactos e manifestações. A pesquisa valeu-se de estudo bibliográfico e de análise documental. A PEC recebeu 28 emendas na Câmara dos Deputados e 65 no Senado Federal, acatadas parcialmente. Foram registradas, dentre outras, manifestações a respeito da constitucionalidade e da perda de recursos; seus defensores alegaram a necessidade de conter gastos em busca do equilíbrio fiscal. A proposta resultou na $\mathrm{EC} \mathrm{n}^{\circ}$ 95/2016 que estabeleceu limites para as despesas primárias, trazendo implicações, dentre outras, para os gastos sociais.
\end{abstract}

Palavras-chave: EC no 95/2016; PEC no 241/2016; PEC n 55/2016; Novo Regime Fiscal; Financiamento da Educação.

\begin{abstract}
This research aims at the processing of the New Fiscal Policy at the National Congress, considering its impacts and manifestations. The research was based on bibliographic studies and documental analysis. The proposition (PEC) received 28 amends on the Deputy Chamber and 65 on the Federal Senate, partially accepted. It was registered, among others, manifestations about the constitutionality and the loss of funds and resources; its defenders claim the necessity of holding back costs aiming fiscal balance. The proposal resulted in the EC \#95/2016 which set limits for primary expenditure, with implications, among others, for social spending.
\end{abstract}

Keywords: EC \#95/2016; PEC \#241/2016; PEC \#55/2016; New Fiscal Policy; Educational Funding.

Resumen: El estudio analiza la tramitación del Nuevo Régimen Fiscal en el Congreso Nacional, considerando sus impactos y manifestaciones. La investigación se valió de estudio bibliográfico y de análisis documental. La PEC recibió 28 enmiendas en la Cámara de Diputados y 65 en el Senado Federal, acatadas parcialmente. Se registraron, entre otras, manifestaciones acerca de la constitucionalidad y de la pérdida de recursos; sus defensores alegaron la necesidad de contener gastos en búsqueda del equilibrio fiscal. La propuesta resultó en la EC 95/2016 que estableció límites para los gastos primarios, con implicaciones, entre otras, para los gastos sociales.

Palabras clave: EC n 95/2016; PEC n 241/2016; PEC n 55/2016; Nuevo Régimen Fiscal; Financiamiento de la Educación. 


\section{INTRODUÇÃO}

A Constituição de 1934 introduziu a vinculação obrigatória no orçamento para a Educação nas três esferas de administração pública. A vinculação foi mantida nas Constituições 1946 e de 1988. As Cartas de 1937 e de 1967 silenciaram quanto à questão e a Emenda Constitucional de 1969 reafirmou a exigência apenas para o nível municipal; em 1983, a Emenda Calmon restaurou a vinculação para todas as esferas, sendo regulamentada em 1985 e entrando em vigor a partir do exercício de 1986. A Constituição Federal de 1988, de acordo com o Art. 212, estabeleceu a vinculação mínima de 18\% para a União e 25\% para os estados, Distrito Federal e municípios, calculados sobre a receita de impostos e de transferências, sendo direcionados para a manutenção e desenvolvimento do ensino. Conforme o Art. 211, da referida Carta, em regime de colaboração, os entes federados organizarão seus sistemas de ensino, sendo estabelecidos os níveis em que atuarão prioritariamente.

Em 2016 o governo federal propôs Emenda à Constituição referente ao Novo Regime Fiscal; o documento tramitou como Projeto de Emenda Constitucional, PEC 241/2016, na Câmara Federal, como PEC 55/2016 no Senado Federal, sendo promulgado como Emenda Constitucional no 95 em 15 de dezembro de 2016. A iniciativa estabelece limites para as despesas primárias correspondentes à inflação do ano anterior, corrigidas pelo IPCA, Índice Nacional de Preços ao Consumidor Amplo. Fica, assim, estabelecida a desvinculação orçamentária para a Educação e Saúde. A medida entra em vigor por duas décadas, podendo ser corrigida a partir do décimo ano.

Considerando a importância da temática, o presente trabalho analisa a tramitação do Novo Regime Fiscal pelo Congresso Nacional bem como manifestações de segmentos e instituições da sociedade civil sobre a mesma. O disciplinamento dos gastos é previsto para todas as áreas; neste artigo, porém, vamos ater-nos à educação.

Os procedimentos metodológicos empregados para a elaboração deste trabalho foram: estudo bibliográfico e análise documental. O primeiro consistiu na consulta de revistas da área acadêmica, em pronunciamentos de entidades da sociedade civil, estudos da assessoria legislativa do Congresso Nacional e imprensa em geral. O segundo consistiu na consulta aos sites oficiais da Câmara dos Deputados, do Senado Federal e do Planalto. 


\section{TRAMITAÇÃO DA EMENDA CONSTITUCIONAL PELO CONGRESSO NACIONAL}

No dia 15 de junho de 2016, os ministros da Fazenda e do Planejamento encaminharam ao Executivo a Proposta de Emenda à Constituição (PEC) que visava instituir um "Novo Regime Fiscal no âmbito da União" (BRASIL, 2016, p. 1). O documento propunha que as despesas orçamentárias, dentre as quais as da Educação e Saúde fossem, por 20 anos, corrigidas pelo Índice Nacional de Preços ao Consumidor Amplo (IPCA) e não mais com vinculações orçamentárias pré-definidas. Na mesma data, sem alterações, a proposta foi encaminhada ao Congresso Nacional,

A PEC, inicialmente assinalada como $\mathrm{n}^{\circ}$ 241/2016, tramitou pelo Congresso Nacional por apenas cento e oitenta e seis dias. Na Câmara dos Deputados, a matéria permaneceu em tramitação por cento e trinta e quatro dias. $\mathrm{Na}$ casa revisora, a matéria foi apreciada em cinquenta e dois dias. Em ambas as casas, houve o registro de pedidos de vista e de votos em separado. Foi possível também identificar atuações destacadas de alguns parlamentares ao longo da tramitação.

\section{A TRAMITAÇÃO PELA CÂMARA DOS DEPUTADOS}

$\mathrm{Na}$ Câmara dos Deputados, a PEC no 241/2016 foi encaminhada para a Comissão de Constituição, Justiça e Cidadania (CCJ) e alguns deputados, notadamente da oposição, propuseram a retirada da matéria de pauta, mas foram vencidos. A comissão aprovou a constitucionalidade da proposta com votos em separado dos deputados Chico Alencar (PSOL-RJ), Daniel Almeida (PCdoBBA), Ivan Valente (PSOL-SP), Luiz Couto (PT-PB), Maria do Rosário (PT-RS), Patrus Ananias (PT-MG) e Rubens Pereira Júnior (PCdoB-MA). Estes evocaram em seus votos o princípio da inconstitucionalidade e do não retrocesso social.

Após a tramitação pela CCJ, a mesa diretora da Câmara dos Deputados constituiu uma Comissão Especial para a apreciação da matéria. Ato contínuo, parlamentares apresentaram quase sessenta requerimentos para que fossem realizadas audiências públicas. Foram ouvidos os ministros da Fazenda, do Planejamento, da Educação e da Saúde, além de educadores e economistas. Também puderam expressar-se representantes da Ordem dos Advogados do Brasil (OAB), da Confederação Nacional dos Bispos do Brasil (CNBB), da União Nacional dos Dirigentes Municipais da Educação (Undime) e do Fórum Nacional de Educação (FNE), entre outras entidades (CÂMARA DOS DEPUTADOS, 2016a). 
$\mathrm{Na}$ tramitação por essa Comissão foram registradas 22 propostas de emendas, tendo os deputados da oposição apresentado cinco propostas. Todas as emendas apresentadas visavam a minimizar o impacto do ajuste fiscal, alterando as formas de cálculo da correção dos valores, a substituição dos percentuais mínimos considerados como piso inicial ou, mesmo, alterações substantivas na proposta do Executivo. Houve até proposições de teto para o desembolso de recursos orçamentários para o pagamento dos juros da dívida pública, fixando-o em, no máximo, cinco pontos percentuais do PIB, de autoria do Dep. André Figueiredo (PDT-CE).

O Dep. Patrus Ananias (PT-MG), que propôs quatro emendas, foi o que apresentou o maior número. As Deputadas Dorinha Seabra (DEM-TO) e Carmen Zanotto (PPS-SC) e o Deputado André Figueiredo (PDT-CE) apresentaram duas emendas cada. Outros doze deputados apresentaram uma proposta de emenda, cada um¹. O relator da Comissão Especial, Dep. Darcísio Perondi (PMDBRS) apresentou seu parecer considerando, ainda que parcialmente, algumas das emendas apresentadas. Tais emendas não alteravam substancialmente o texto original. Em seu parecer, o relator apontou: "caso nada seja feito, o Dia do Juízo Fiscal chegará e atingirá a todos: famílias, aposentados, funcionários públicos e empresários" (CÂMARA DOS DEPUTADOS, 2016b, p.24), o que evidencia seu alinhamento à proposta do Executivo. Foram registrados pedidos de vista por diversos deputados ${ }^{2}$ e foram registrados votos em separado, como o do Dep. Patrus Ananias (PT-MG) e da Dep. Luciana Santos (PCdoB-PE).

Após a tramitação pela Comissão Especial, a matéria retornou ao plenário da Câmara dos Deputados, quando, mais uma vez, líderes da oposição apresentaram requerimentos para a retirada da proposta da PEC da pauta, tendo, no entanto, sido vencidos. Foram registrados também requerimentos e destaques que visavam à prorrogação do tempo da tramitação, todos rejeitados. As deputadas Erika Kokay (PT-DF) e Moema Gramacho (PT-BA) apresentaram três emendas cada, todas rejeitadas. Após a apreciação do parecer em dois turnos, o mesmo foi aprovado por trezentos e vinte e cinco deputados, tendo oitenta e nove deputados se manifestado contrários à matéria e um parlamentar se abstido. O texto da PEC

1 Dep. Bacelar (PTN-BA), Dep. Daniel Almeida (PCdoB-BA), Dep. Félix Mendonça Junior (PDTBA), Dep. Marcelo Aro (PHS-MG), Dep. Marcus Pestana (PSDB-MG), Dep. Major Olímpio (SD-SP), Dep. Mauro Benevides (PMDB-CE), Dep. Pedro Cunha Lima (PSDB-PB), Dep. Rogério Rosso (PSD-DF), Dep. Silvio Torres (PSDB-SP), Dep. Valtenir Pereira (PMDB-MT) e Dep. Weverton Rocha (PDT-MA).

2 Dep. Alessandro Molon (REDE-RJ), Dep. Altineu Côrtes (PMDB-RJ), Dep. André Figueiredo (PDT-CE), Dep. Arthur Oliveira Maia (PPS-BA), Dep. Carlos Marun (PMDB-MS), Dep. Cristiane Brasil (PTBRJ), Dep. Erika Kokay (PT-CE), Dep. Henrique Fontana (PT-RS), Dep. Hildo Rocha (PMDB-MA), Dep. Jorge Solla (PT-BA), Dep. Julio Lopes (PP-RJ) e Dep. Luciana Santos (PCdoB-PE). 
foi alterado apenas em relação à forma do cálculo das aplicações mínimas e ao exercício fiscal para a atualização pelo IPCA (CÂMARA DOS DEPUTADOS, 2016a).

\section{A TRAMITAÇÃO PELO SENADO FEDERAL}

No Senado Federal, já com nova denominação, PEC no 55/2016, a proposta, após ser lida em plenário, foi encaminhada à Comissão de Constituição, Justiça e Cidadania (CCJ). Nesta Comissão, em que o Senador Eunício Oliveira (PMDB-CE) foi designado relator, uma vez mais foram registrados requerimentos para audiências públicas e pedidos de vistas.

Ainda durante a tramitação pela CCJ, os senadores Roberto Requião (PMDB-PR) e Randolfe Rodrigues (REDE-AP) apresentaram votos em separado, tendo o primeiro também evocado, a exemplo do que havia ocorrido na Câmara dos Deputados, entre outros, os princípios constitucionais do não retrocesso social e da razoabilidade (SENADO FEDERAL, 2016b) como fundamentos para uma nova PEC. O segundo senador, refletindo sobre o que denominou de "congelamento da democracia", destacou o impacto do proposto no texto original da PEC quando, no futuro, o Brasil retomar o crescimento:

Em uma situação de retomada de crescimento e de recuperação do equilíbrio fiscal, não há motivos para não incorporar o aumento do PIB e, portanto, os ganhos de arrecadação, às políticas sociais, ao menos parcialmente (SENADO FEDERAL, 2016C).

Os votos em separado não lograram êxito. Foram registradas cinquenta e nove propostas de emendas ao longo da tramitação na CCJ, porém o relator rejeitou todas. Quase a totalidade das propostas foi de autoria dos senadores do bloco oposicionista. Sete senadores do Partido dos Trabalhadores (PT) propuseram quarenta e quatro emendas ${ }^{3}$. A senadora Vanessa Grazziotin (PCdoBAM) apresentou oito propostas de emendas.

Três senadores da base governista, Hélio José (PMDB-DF), Dário Berger (PMDB-SC) e João Capiberibe (PSB-AP), apresentaram, juntos, sete emendas. Entre as propostas de emendas do bloco oposicionista, pode-se destacar: a propositura de referendo popular para a aprovação do teor da PEC; a redução do prazo de vigência do Novo Regime Fiscal para cinco anos; a adoção de limite individualizado para a despesa com juros e encargos da dívida pública da União;

3 Senador Paulo Paim (PT-RS) - 14, Senadora Ângela Portela (PT-RR) - 7, Senador José Pimentel (PT-CE) - 7, Senador Lindbergh Farias (PT-RJ) - 6, Senador Humberto Costa (PT-PE) - 5, Senadora Fatima Bezerra (PT-RN) -4 e Senadora Gleisi Hoffman (PT-PR) -1. 
alterações no congelamento das despesas quando o país registrar ao menos quatro trimestres consecutivos de crescimento do PIB, entre outras.

As emendas de autoria dos senadores da base de apoio do Executivo previam: o não congelamento dos salários dos servidores lotados na área tributária da União e a manutenção dos aumentos salariais para servidores previstos na legislação em vigor; diferente forma de cálculo para o piso destinado à saúde no primeiro ano de vigência do regime fiscal; redução da vigência do Novo Regime Fiscal; consideração sobre os limites constitucionais dos recursos destinados para a educação e saúde como piso para o posterior congelamento, entre outras propostas.

O relatório do Senador Eunício Oliveira (PMDB-CE) foi aprovado na CCJ por dezenove senadores. Sete senadores votaram contra o parecer do relator. O texto enviado pela Câmara dos Deputados foi, então, considerado como constitucional e não incorporou nenhuma sugestão.

Já no plenário, no primeiro turno da votação, foram apresentadas seis propostas de emendas. Os senadores Pastor Valadares (PDT-RO), Telmário Mota (PDT-RR) e Lasier Martins (PDT-RS) apresentaram emenda pela exclusão dos recursos vinculados para Saúde, Educação e Assistência Social do limite global de gastos. O Senador Cristovam Buarque (PPS-DF) apresentou emenda em que buscava assegurar, no mínimo, o valor real do gasto em Educação de 2017 como piso para a aplicação da correção. O senador Paulo Paim (PT-RS) apresentou emenda visando a excluir as despesas com Seguridade Social ${ }^{4}$ do limite imposto pelo novo teto de gastos. A senadora Vanessa Grazziotin (PCdoB-AM) propôs limites orçamentários também para o desembolso com o pagamento de juros da dívida pública. O senador Randolfe Rodrigues (REDE-AP) propôs a submissão do teor da PEC a referendo popular. A senadora Kátia Abreu (PMDB-TO) propôs a redução do prazo de vigência do Novo Regime Fiscal. Todas as emendas foram desconsideradas ou por insuficiência no número de assinaturas para a proposta ou porque foram rejeitadas pelo Senador Eunício Oliveira (PMDB-CE).

No primeiro turno, o texto da PEC foi aprovado, sem alterações, por ampla maioria. Dos setenta e seis senadores presentes, sessenta e um aprovaram o relatório; não se verificou o registro de abstenções. Menos de quinze dias depois, a PEC foi novamente apreciada, desta vez em segundo turno. Cinquenta e três senadores foram favoráveis ao texto, dezesseis foram contrários e foi registrada uma abstenção.

A PEC foi promulgada como Emenda Constitucional no 95/2016, no dia 15 de dezembro de 2.016 .

4 A Seguridade Social compreende os gastos com Saúde, Previdência e Assistência Social. 
A tramitação pelo Congresso, em período relativamente curto, foi marcada pela supremacia das bancadas alinhadas ao governo e pela manutenção, quase incólume, do texto original, com alterações apenas formais na redação, ou seja, a intenção contida na Exposição de Motivos Interministerial, EMI, dos ministros da área econômica prevaleceu no diploma legal. Foi possível perceber que parlamentares com atuação em favor da Educação, quando da tramitação de outras matérias, como o PNE (Lei no 13.005/2014) mantiveram uma postura no sentido de assegurar recursos para a área.

Outro ponto de destaque foi a preocupação, manifestada em diversas emendas das duas casas legislativas com os recursos destinados ao pagamento de juros da dívida pública, que acabam por pressionar o orçamento do governo de forma crescente, uma vez que a dívida pública tem crescido de forma substantiva, em especial pela adoção da taxa de juros real que é uma das mais altas do mundo.

\section{MANIFESTAÇÕES EM RELAÇÃO AO NOVO REGIME FISCAL}

Foram registradas manifestações em relação à proposta governamental feitas por acadêmicos, economistas, assessores legislativos e entidades da sociedade civil em audiências públicas no Congresso Nacional, em publicações acadêmicas e em órgãos de imprensa. Apresentamos, sem a pretensão de esgotálos, os principais argumentos favoráveis e contrários à PEC; as manifestações foram selecionadas considerando os referidos argumentos.

$\mathrm{Na}$ carta enviada ao então vice-presidente em exercício, como justificativa para a edição da PEC, os ministros da Fazenda e do Planejamento, Desenvolvimento e Gestão enfatizam que o "instrumento visa [a] reverter, no horizonte de médio e longo prazo, o quadro de agudo desequilíbrio fiscal em que nos últimos anos foi colocado o Governo Federal"; acrescentam que a iniciativa "é essencial para recolocar a economia em trajetória de crescimento com a geração de renda e empregos", além de que "estimulará a aplicação eficiente de recursos públicos" (BRASIL, 2016).

A medida proposta visa a estabelecer "regras que contenham a pressão por expansão do gasto além da capacidade de pagamento do governo" e "recobrar o equilíbrio fiscal com visão de longo prazo" (MEIRELLES, 2016). A necessidade da medida é reconhecida, considerando-se que, "Nas duas últimas décadas, o gasto primário tem crescido a uma taxa muito acima do crescimento do PIB, o que aponta para uma trajetória fiscal insustentável, caso não sejam adotadas medidas de ajuste" (VELOSO, 2016). O reequilíbrio das contas redundará na 
recuperação da economia a qual possibilitará conter o desemprego e a inflação (MENDES, 2016) e proporcionará a recuperação da "capacidade fiscal do Estado brasileiro" evitando que se perca o que foi construído (PESSOA, 2017).

A fixação de limites para as despesas públicas é a tônica da proposta. Em decorrência do pressuposto, apesar de não ter sido estabelecida a desvinculação dos recursos financeiros prevista constitucionalmente para as áreas de Educação e Saúde, na prática não podemos esperar que essas áreas sociais sejam priorizadas no contexto do Poder Executivo. A medida constituiu-se em um dos pontos polêmicos da inciativa, considerando os movimentos historicamente registrados para sua incorporação constitucional, o estabelecido em exercícios anteriores, os desafios enfrentados pelas áreas e o atendimento das mesmas à população mais pobre.

Defendendo a desvinculação, Veloso (2016) afirma que "Na medida em que grande parcela do orçamento é fixada por lei e regras de indexação, a margem de escolha do governante para executar políticas defendidas na campanha é muito limitada". O argumento apresentado não resiste à análise uma vez que o Novo Regime Fiscal tem implicações igualmente restritivas porque retira da sociedade e do parlamento "a prerrogativa de moldar o tamanho do orçamento público, que passará a ser definido por uma variável econômica (a taxa de inflação), e impor uma política permanente de redução relativa do gasto público" (FÓRUM 21, 2016, p.10).

Na Exposição de Motivos, afirma-se que é necessária a desvinculação “justamente para evitar que nos momentos de forte expansão econômica seja obrigatório o aumento dos gastos nessas áreas e, quando da reversão do ciclo econômico, os gastos tenham que desacelerar bruscamente" (BRASIL, 2016). Certamente não é esse o motivo central que levou à desvinculação, a qual se deu como medida de contenção nos gastos sociais, como se depreende da análise da proposta, da Exposição de Motivos e das simulações que serão apresentadas.

VELOSO (2016) acrescenta que a vinculação “deveria ser uma exceção e não a regra" e que a mesma deveria "ser limitada no tempo e condicionada a uma avaliação periódica". Sobre o assunto Pessoa (2016) afirma que "Vale lembrar que nos últimos dez anos o gasto per capita com saúde cresceu 40\% e com educação $100 \%$ ". No entanto, continua, "Não houve melhora de qualidade equivalente". Se, no caso da Educação, os problemas em relação à qualidade e cobertura continuam desafiando o executivo, não é diminuindo os recursos que os mesmos serão resolvidos. Por outro lado, uma avaliação que se faça deve considerar a infraestrutura, a formação, a experiência e as condições de trabalho do pessoal docente e de apoio administrativo e as condições de vida dos alunos; enfim, a avaliação é uma atividade bastante complexa. 
O estabelecimento da vinculação de recursos financeiros para a educação e sua continuidade em períodos democráticos procura superar os deficits na área e garantir o direito constitucional à educação, possibilitando a oferta, manutenção e desenvolvimento do ensino de qualidade. Nesse sentido, a PEC foi considerada inconstitucional. por violar cláusula pétrea (SENA, 2016; VIEIRA JÚNIOR, 2016). A constatação da violação, conforme Sena (2016) se dá considerando que "a vinculação é um princípio constitucional que enseja a intervenção federal (Art. 34, VII, e), sob a qual sequer pode ser apreciada qualquer emenda constitucional (Art. 60, $\$ 1^{\circ}$ ADCT)". Vieira Júnior (2016) conclui que a proposta é inconstitucional uma vez que viola, dentre outros, os princípios da separação dos poderes, da razoabilidade e do retrocesso social. A nota da ANPAE et al (2016) denuncia que a iniciativa representa a desconstrução do Art. 212 da Constituição Federal.

A vinculação orçamentária representa garantia de aportes, uma vez que, nos anos em que a mesma não foi exigida, verificou-se uma diminuição de recursos; a este respeito vale lembrar as análises realizadas por Melchior (1987) a respeito do declínio dos recursos da União para a função Educação e Cultura no período de 1967 a 1971; a partir de então, "começou uma tendência de aumento nos dispêndios... embora essa tendência não seja transparente" (p 66); no período analisado, não havia obrigação constitucional de vinculação para a esfera federal.

Simulações feitas a partir da Proposta evidenciam perdas de recursos para a área educacional em anos posteriores a 2017, caso a regra válida para o Poder Executivo seja aplicada para a área educacional sem priorizá-la. Amaral (2016), considerando que as três esferas de governo aplicaram o correspondente a 6\% do PIB em 2014, verificou que esse total se reduzirá para 5\% em 2024. A FINEDUCA, em sua Nota n¹/2016, apresentou um estudo dos gastos federais com Educação a partir da aplicação "de um percentual de 18\%, considerando-se um crescimento da receita real de 3\% ao ano, após 5 anos a vinculação já estaria em 16\%; após 10 anos, em 13,8\% e após 20 anos chegaria a 10,3\%, ou seja, uma redução de 43\% no índice". Silva (2016), igualmente, apresentou uma simulação que evidencia a perda de recursos, partindo de 6,34\% do PIB em 2018 para 5,16\% em 2023. Estudo apresentado pelo Fórum 21 (2016 p. 9) evidencia que a proposta implica em "reduzir a despesa primária do governo federal de cerca de $20 \%$ do PIB em 2016 para algo próximo de 16\% do PIB até 2026 e de 12\% em 2036". Mendlovtz (2016) apresentou um estudo no qual a área teria uma perda de 9,6\% em 2016, "caso a regra tivesse sido aplicada em 2010 com vigência a partir de $2011 "$ (p. 3).

As diferentes simulações evidenciam a diminuição de recursos para a área da Educação. Assim, inviabiliza-se o atingimento de metas do Plano Nacional de Educação, as quais preveem, dentre outras, atingir o patamar mínimo de 7\% do 
PIB a ser aplicado na área em até 2019 e 10\% no final de vigência do mesmo, ou seja, 2024. Inviabilizam-se também as estratégias referentes à implantação do Custo Aluno Qualidade inicial (CAQi) - e a implementação plena do Custo Aluno Qualidade (CAQ). A cobertura também é inviabilizada, considerando que o sistema educacional não estendeu a todos a inclusão (ANPAE et al, 2016; AMARAL, 2016; FINEDUCA, 2016; FNE, 2016; FÓRUM 21, 2016; MENDLOVTZ, 2016; SILVA, 2016; UNDIME, 2016).

O Ministro da Fazenda afirma que o gasto com Educação e Saúde "será bastante acima do mínimo" e que o mesmo "não será cortado abruptamente" (MEIRELLES, 2016). A afirmação não convence uma vez que não considera os problemas enfrentados e os desafios que ainda estão presentes; igualmente, não tranquiliza, ao admitir que haverá corte, ainda que o mesmo não se dê abruptamente.

Há um consenso sobre o reconhecimento da situação de crise que vive o país. Porém, a proposta do Novo Regime Fiscal como solução para a mesma não é aceita por todos. A CNBB considerou a solução encontrada "injusta e seletiva", porque "beneficia os detentores do capital financeiro, quando não coloca teto para pagamento de juros, não taxa grandes fortunas e não propõe auditar a dívida pública" (2017). O FNE propõe "a revisão do marco regulatório tributário nacional com vistas a ampliar a arrecadação de impostos sobre a renda, o lucro e o patrimônio dos que detêm a riqueza nacional, regulamentando, inclusive, o Imposto sobre Grandes Fortunas" (2016). O documento do FÓRUM 21 (2016) reconhece que houve aumento da carga tributária a qual "alcançou 32,7\% do PIB em 2013"; porém, reconhece que a "estrutura de tributação é extremamente perversa com os mais pobres e a classe média e benevolente com os mais ricos". A crise, reconhecem os documentos citados, está na receita e não na despesa. O Ministro da Fazenda pensa de maneira diferente ao rechaçar o aumento de impostos, de maneira linear ou selecionada, nesse sentido afirmou que "nossa carga tributária já está entre as mais altas do mundo" (MEIRELLES, 2016).

A UNDIME (2016) manifestou-se em relação ao Novo Regime Fiscal registrando que "tem a compreensão de que esta medida repercutirá na redução dos investimentos públicos em educação pública". Acrescenta que a iniciativa "enfraquece o princípio constitucional de colaboração entre os entes federados". A preocupação maior é em relação à continuidade da política de fundos instituída pelo FUNDEF e continuada pelo FUNDEB, este com vigência até o ano de 2020. Nesse sentido, fica uma interrogação em relação ao financiamento da Educação Básica após este período. Uma solução aventada reside na transformação do FUNDEB em instrumento permanente de financiamento da Educação Básica pública, conforme a PEC 15-A de 2015 em tramitação na Câmara Federal. 
Os gastos, tanto na Educação quanto na Saúde, "beneficiam milhões de brasileiros que não podem pagar por esses serviços” e os defensores da causa "têm menor poder de barganha no Congresso" (MENEZES FILHO, 2016). Daí, a preocupação com a garantia de mínimos de qualidade para a área. A Proposta parecer pressupor que todos os problemas da área estão resolvidos e que, a partir de agora, basta racionalizar os gastos. Está implícita a afirmação de que os recursos existem e são mal geridos; discurso repetido, não condizente com a realidade, omisso em relação às necessidades e justificador para a contenção de gastos.

Contrariando o discurso de que a dotação orçamentária é suficiente, no que concerne à Educação, continuam presentes desafios: o atendimento à demanda; a universalização da Educação Básica obrigatória na faixa dos quatro aos dezessete anos; o oferecimento da infraestrutura mínima que se requer de uma escola em nossa época; a qualificação e a garantia de mínimos para os recursos humanos envolvidos no oferecimento, manutenção e desenvolvimento do ensino; enfim, prover do que se faz necessário para assegurar a qualidade de ensino da escola pública.

\section{CONSIDERAÇÕES FINAIS}

São patentes, quando da análise da tramitação da PEC nº 241/2016 pelo Congresso Nacional, a sanha do governo e de parlamentares alinhados ao mesmo pela 'minimização' do Estado para o financiamento da Educação e Seguridade Social. Para tais agentes públicos, a Constituição 'Cidadã' inviabiliza o funcionamento do Estado brasileiro em função, principalmente, dos investimentos mínimos então definidos. Por outro lado, comparações da arrecadação de receitas em razão do PIB do Brasil com outras nações em desenvolvimento ou já desenvolvidas denunciam que o país arrecada mais do que a média e retorna, através da oferta de serviços públicos, muito menos do que o grupo de países utilizados para a comparação.

Um dos itens que mais evidencia que há um desequilíbrio entre o arrecadado e as necessidades de custeio e investimento é o valor destinado para o pagamento dos juros da dívida pública, que representou 42,43\% do Orçamento Geral da União em 2015 (FATTORELLI, 2016), valor que pode chegar aproximadamente a cinquenta por cento anualmente, conforme estimativas. Justamente por isso, pode-se notar, no presente trabalho, a atenção de muitos parlamentares, em especial senadores, para com tal questão. Já há algum tempo, os cortes orçamentários recaem sobre os investimentos e custeio do Estado. A Desvinculação de Receitas da União (DRU), adotada desde a década de 1990 é 
um dos dispositivos flexibilizadores do custeio de despesas sociais; na mesma direção, seguem 'contribuições' criadas ao invés de impostos.

A opção mais frequente, historicamente verificada, tem sido pelo corte indiscriminado de despesas e pelo persistente aumento da carga tributária. Ao que parece, temas relacionados com os desperdícios ou ineficiência do Estado são secundarizados e quase nunca considerados. As decisões políticas quase sempre recaem apenas na minimização das despesas que, quase sempre, alcançam os mais necessitados e as áreas sociais, que já foram, no passado recente, uma das alavancas do desenvolvimento econômico e social do país.

A força da bancada governista, então majoritária, demonstrada no processo, garantiu a tramitação célere da PEC e a manutenção da Proposta inicial com pequenas alterações, limitadas apenas a aspectos formais. Não foram considerados os argumentos contrários de inconstitucionalidade, as simulações que evidenciaram as perdas para a área educacional, o não atendimento a metas e estratégias do PNE, as propostas de diminuição do prazo de vigência da medida tampouco outras sugestões e manifestações de segmentos representativos da sociedade civil. A inexistência da vinculação orçamentária, conforme demonstrado historicamente, redundou na drástica diminuição de recursos para a educação; considerando-se a situação da área e os deficits acumulados é de se prever a postergação da oferta, manutenção e desenvolvimento do ensino de qualidade para todos.

A Emenda Constitucional $n^{\circ}$ 95/2016 foi contestada no Supremo Tribunal Federal por ADI, Ação Direta de Inconstitucionalidade, em sete processos, elencados por ordem cronológica: ADI 5633, requerida pela Associação dos Magistrados Brasileiros (AMB), pela Associação Nacional dos Magistrados da Justiça do Trabalho (ANAMATRA) e pela Associação dos Juízes Federais do Brasil (AJUFE); ADI 5643, movida pela Federação Nacional dos Servidores e Funcionários Públicos (FENASEPE); ADI 5655 solicitada pela Associação Nacional dos Membros do Ministério Público (CONAMP), pela Associação Nacional dos Procuradores da República (ANPR) e pela Associação Nacional dos Procuradores do Trabalho (ANPT); ADI 5658, solicitada pelo Partido Democrático Trabalhista (PDT); ADI 5680, de iniciativa do Partido Socialismo e Liberdade (PSOL); ADI 5715, requerida pelo Partido dos Trabalhadores (PT); e ADI 5734 solicitada pela Confederação Nacional dos Trabalhadores em Educação (CNTE). Essas ações denunciam vícios de ordem formal e material na Emenda Constitucional (SUPREMO TRIBUNAL FEDERAL, 2017). Por fugirem ao objetivo da pesquisa, deixamos de analisar cada uma das peças. 


\section{REFERÊNCIAS}

AMARAL, Nelson C. PEC 241: A “morte" do PNE (2014-2014) e o poder de diminuição dos recursos educacionais. Goiânia: Revista Brasileira de Política e Administração da Educação, v.32, n.3, set./dez. 2016, p. 653-673.

ANPAE et alii. Manifesto contra a PEC no 241/2016. Disponível em < http:/ / www.anped.org.br/biblioteca/item/manifesto-contra-pec-no-2412016-pne-emrisco $>$. Acesso em 26 de janeiro de 2016.

BRASIL. Emenda Constitucional $\mathbf{n}^{\mathbf{0}} \mathbf{9 5}$, de 15 de dezembro de 2016. Altera o Ato das Disposições Constitucionais Transitórias para instituir o Novo Regime Fiscal e dá outras providências.

Lei $\mathbf{n}^{\mathbf{0}}$ 13.005, de 25 de junho de 2014. Aprova o Plano Nacional de Educação - PNE e dá outras providências.

. Exposição de Motivos Interministerial, EMI n ${ }^{\circ}$ 00083/2016 MF MPDG. Brasília, DF: 2016.

.FÓRUM NACIONAL DE EDUCAÇÃO. $44^{a}$ Nota Pública. Disponível em: <https://undime.org.br/noticia/29-09-2016-12-10-forum-nacional-deeducacao-se-posici ona-por-meio-de-notas-publicas-sobre-a-bncc-o-corte-etarioe-a-pec-241>. Acesso em: 27 de janeiro de 2017.

CÂMARA FEDERAL. Emendas apresentadas à PEC $\mathbf{n}^{\circ}$ 241, de 2016. Brasília, DF, 2016a. Disponível em: <http://www.camara.gov. br/proposicoesWeb/prop_ _ emendas;jsessionid=B50358333E08E4958E DD521493436629.proposicoesWebExterno1?idProposicao=2088351\&sub st $=0>$. Acesso em: 28 de janeiro de 2017.

. CÂMARA FEDERAL. Parecer do Relator da Comissão Especial da PEC n $^{\circ}$ 241, de 2016. Brasilia, DF, 2016b. Disponível em: < http:/ /www.camara. gov.br/proposicoesWeb/prop_mostrarintegra;jsessionid=0A941D8BD8A6CCE 7A8BD730886DBB276.proposicoes WebExterno1?codteor=1495741\&filename =Tramitacao-PEC+241/2016>. Acesso em 09 de agosto de 2017. 
CÂMARA FEDERAL. PEC 15- A. Insere parágrafo único no art. 193; inciso IX, no art. 206 e art. 212-A, todos na Constituição Federal. Disponível em <http://www.camara.gov.br/proposicoesWeb/fichadetramitacao?idProposic ao $=1198512$. Acesso em 02 de agosto de 2017.

SENADO FEDERAL. Proposta de Emenda à Constituição $\mathbf{n}^{\circ}$ 55, de 2016 - PEC do teto dos gastos públicos. Brasília, DF, 2016. Disponível em: $<$ https://www25.senado.leg.br/web/atividade/materias/-/materia/127337>. Acesso em 29 de janeiro de 2017.

SENADO FEDERAL. Voto em separado na CCJ - Senador Roberto Requião - PEC do teto dos gastos públicos. Brasília, DF, 2016b. Disponível em: $<$ https://legis.senado.leg.br/sdleg-getter/documento?dm=3878542\&disposition $=$ inline $>$.

SENADO FEDERAL. Voto em separado na CCJ - Senador Randolfe Rodrigues - PEC do teto dos gastos públicos. Brasília, DF, 2016c. Disponível em: $<$ http://legis.senado.leg.br/sdleg-getter/documento?dm=3878533\&disposition $=$ inline $>$.

. SUPREMO TRIBUNAL FEDERAL. Disponível em http://www. stf.jus.br/portal/peticaoInicial/pesquisarPeticaoInicial.asp. Acesso em $14 \mathrm{de}$ setembro de 2017.

CNBB - Conferência Nacional dos Bispos do Brasil. CNBB divulga nota sobre a PEC 241. Disponível em <https://noticias.cancaonova.com/brasil/cnbbdivulga-nota-sobre-pec-241/>. Acesso em 31 de janeiro de 2017.

FATTORELLI, M. L. Explicação sobre o gráfico do orçamento elaborado pela Auditoria Cidadã da Dívida. Disponível em: < http:/ / www.auditoriacidada. org.br/blog/2016/11/09/explicacao-sobre-o-grafico-do-orcamento-elaboradopela-auditoria-cdada-da-divida/>. Acesso em 24 e janeiro de 2017.

FINEDUCA. Carta de São Paulo. Disponível em: <http://www.finenduca. org.br/index/2016/08/carta-de-são-paulo-iv-encontro-fineduca/>. Acesso em: 23 de janeiro de 2017. 
F.N.E. - Fórum Nacional de Educação: $44^{a}$ Nota Pública do F.N.E. Disponível em: <https://www.cedes.unicampo.br/d1/1/ACawjAO_2b68c_>. Acesso em 30 de janeiro de 2017.

FÓRUM 21. Austeridade e Retrocesso. São Paulo: Fórum 21, 2016. Disponível em: $\quad<$ http://brasildebate.com.br/wp-content/uploads/Austeridade-eRetrocesso.pdf $>$. Acesso em: 30 de janeiro de 2017.

MEIRELLES, Henrique. PEC 241/2016 e o Novo Regime Fiscal do Brasil. Disponível em <http://www.fazenda.gov.br/centrais-de-conteudos/ apresentacoes/2016/2016-08-24-apresentacao-pec-241-2016-ministro/view>. Acesso em: 28 de janeiro de 2017.

MELCHIOR, José C. de A. O financiamento da Educação no Brasil. São Paulo: EPU, 1987.

MENDES, Marcos. Os 7 mitos sobre a PEC do teto. Disponível em: <http:/ / www.fazenda.gov.br/centrais-de-conteudos/apresentacoes/2016/senado_os-7mitos-sobre-a-pec-do-teto.pdf $>$. Acesso em: 29 de janeiro de 2017.

MENDLOVTZ, Marcos R. R. CONOF - Estudo Técnico $\mathbf{n}^{\circ}$ 11. Disponível em: < <http://www.deolhonosplanos.org.br/wp-content/uploads/2016/09/ Estudo-Tecnico-11-de-2016_Analise-dos-efeitos-da-PEC-241-sobre-a-MDE. pdf $>$. Acesso em: 26 de janeiro de 2017.

MENEZES FILHO, Naercio. Conta será paga pelos mais pobres. São Paulo: Folha de São Paulo, p. A3, 11 de junho de 2016.

PESSOA, Samuel de A. Audiência pública da Comissão de Justiça do Senado Federal. Disponível em: <http://legis.senado.leg.br/comissoes/reuniao?reuniao $=5598 \&$ codcol $=38>$. Acesso em 28 de janeiro de 2017 .

SENA, Paulo. Impactos da PEC 241 no financiamento da Educação. Disponível em: < https://pt.scribd.com/document/330867367/IMPACTOSDA-PEC-N\%C2\%BA-241-No-Financiamento-Da-Educacao-Paulo-Sena $>$. Acesso em: 26 de janeiro de 2016. 
SILVA, Guaracy. Políticas de Financiamento do Governo Temer para o Ensino Superior: primeiras impressões. $\mathbf{6}^{\mathbf{a}}$ Conferência FORGES. Campinas, SP. 2016.

UNDIME. Nota da UNDIME sobre a PEC 241/2016. Disponível em $<$ https://undime.org.br/noticia/27-10-2016-16-54-nota-da-undime-sobre-apec-241-2016>. Acesso em 27 de janeiro.de 2017.

VELOSO, Fernando. Democracia e eficácia no gasto público. São Paulo: Folha de São Paulo, p. A3, 11 de junho de 2016.

VIEIRA JR., Ronaldo J.A. As inconstitucionalidades do "Novo Regime Fiscal" instituído pela PEC 55 de 2016. Disponível em: <http:/ /www2.senado. leg.br/bdsf/handle/id/525609>. Acesso em 27 de janeiro de 2017.

CLEITON DE OLIVEIRA possui graduação em Pedagogia pela atual UNIMEP (1972), mestrado em Educação pela mesma instituição (1983) e doutorado em Educação pela UNICAMP (1992). Foi docente no ensino básico de 1964 a 1976; no ensino superior lecionou de 1973 a 2012, tendo atuado na UNIMEP, UNICAMP e UNISO. Além da docência exerceu cargos administrativos na UNIMEP (Chefe do Departamento de Educação, Coordenador do Curso de Pedagogia, Diretor do Centro de Ciências Humanas e Coordenador do Programa de Pós-Graduação em Educação. Foi dirigente Municipal de Educação do município de Santa Bárbara d’Oeste; atuou como Conselheiro Suplente no Conselho Estadual de Educação, tendo assumido como titular na maior parte do mandato (1989-1991). Foi membro fundador da UNDIME (1986), tendo ocupado o cargo de presidente do Conselho da entidade no estado de São Paulo (1986-1988). Tem experiência em educação, com ênfase em Política Educacional, atuando principalmente nos seguintes temas: legislação do ensino, descentralização, municipalização, relações intergovernamentais, financiamento do ensino e organização educacional. Atualmente é docente colaborador no Programa de Pós-Graduação em Educação na UNIMEP e pesquisador do LAGE - Laboratório de Gestão Educacional da Faculdade de Educação da UNIMEP. E-mail: cleitondeoli@gmail.com

GUARACY SILVA é doutor em Educação pela UNIMEP (2015) tendo realizado estágio sanduíche na Universidade de Lisboa (2013). Possui graduação em Administração de Empresas pela Sociedade Riopretense de Ensino Superior (1996) e mestrado em Administração pelo Centro Universitário de Franca - 
UNIFACEF (2005). Atualmente é superintendente corporativo do Grupo Educacional UNIS e professor dos programas de graduação e pós-graduação da mesma instituição. Pesquisa temas relacionados a gestão de instituições de ensino superior, tendências na oferta do ensino superior, políticas públicas para o ensino superior, em especial o PNE, políticas públicas voltadas para a seguridade social. E-mail: gsilva@unis.edu.br

Recebido em outubro de 2017

Aprovado em março de 2018 